\title{
USING THE CAPABILITIES OF NEW TECHNOLOGIES TO PRESERVE AND PROMOTE THE THRACIAN CULTURAL HERITAGE
}

\author{
Vesela Georgieva \\ Faculty of Philosophy, University of Sofia "St. Kliment Ohridski", Bulgaria \\ vessy95georgieva@gmail.com
}

\begin{abstract}
The paper presents opportunities to preserve the Thracian cultural heritage associated with the Thracian Valley, using the potencial of new technologies. The results of the study of the process are presented, related to the socialization of the museum sites, who are important for the development of the culture and tourism in the Kazanlak region and the need to introduce practices to attract different types of museum audiences. Positive practices have been identified towards the application of modern information and communication technologies, relating to presentation and promotion of the Thracian cultural heritage and improving the service that promotes the visitation of museum sites from the Valley of the Thracian Kings by paying special attention to providing intellectual access to all of them and the application of modern ICT.Prospects for preservation and promotion of the Thracian cultural heritage related to the Valley of Thracian rulers are presented, among them providing intellectual access to museum sites from the Kazanlak region and applying practices that provide opportunities for innovations, interactive forms, virtual walks, use of technological walks, virtual and mixed reality solutions and other innovations related to contemporary ICT in museums.
\end{abstract}

Keywords: Thracian Heritage; Socialization; Information Technology

\section{ИЗПОАЗВАНЕ ВЪЗМОЖНОСТИТЕ НА НОВИТЕ ТЕХНОЛОГИИ ЗА СЪХРАНЯВАНЕ И ПОПУАЯРИЗИРАНЕ НА ТРАКИЙСКОТО КУАТУРНО НАСАЕАСТВО}

\author{
Весела Георгиева \\ Софрийски университет „Св. КА. Охрилски“, България
}

\begin{abstract}
Резюме: В АОкАаАа се преАставят възможности за съхраняване на тракийското културно наслеАство, свързано с Аолината на тракийските влалетели чрез използване на възможностите на новите технологии. Представят се резултати от изследване на процесите, свьрзани сьс социализацията на музейните обекти, които имат важно значение за развитието на културата и туризма в Казан^ьшкия регион и необходимостта от въвежлане на практики за привличането на различни вилове
\end{abstract}


музейна публика. Установени са положителни практики в посока на прилагането на съвременни инорормационни и комуникационни технологии, отнасящи се $А$ представяне и промотиране на тракийското културно наследство, подобряване на обслужването и насърчаване на посещаемостта на музейните обекти от Аолината на тракийските царе, чрез отАелянето на специално внимание върху осигуряването на интелектуален Аостьп АО всички тях и приложение на съвременните ИКТ. Изведени са перспективи за съхраняване и популяризиране на тракийското културно наслеАство, Свързано С Аолината на тракийските влалетели, среА които осигуряването на интелектуален Аостьп АО музейните обекти от Казанльшкия регион. На базата на контент анализ на Аокументи и меАийни публикации е установено прилагането на практики, предоставящи възможности за нововъведения, интерактивни форми, виртуални разходки, използване на технологични решения с виртуална и смесена реалност и Аруги иновации, свързани със съвременните ИКТ в музеите.

КАючови Ауми: Тракийско наслеАство, социализация, инорормационни технологии

\section{Въведение}

През последните десетилетия се наблюАава бързо развитие на съвременните инорормационни и комуникационни технологии, намиращи приложение в музеи, библиотеки, архиви и Аруги институции

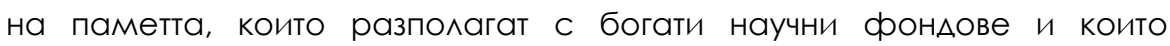
използват тези технологии с цел $а$ а се улесни както научната им обработка, така и тяхното популяризиране. Процесите, свързани със социализацията на музейните обекти, имат важно значение порали редица фоктори. Някои от тях се отнасят към развитието на културата и туризма, необхолимостта от въвежлане на практики за привличането на различни вилове музейна публика, вкАючително повече мАаАи хора в музейните обекти и Аруги. Всичко това би могло $\Delta а$ бъде реализирано частично чрез въвежлането и прилагането на повече съвременни инфоомационни и комуникационни технологии в сорерата на културата.

\section{Актуалност и значимост на темата}

Община Казанльк има значителен потенциал за развитие на туризма и през годините полага послеАоватеАни и целенасочени усилия в посока за превръщането на Казанльк в атрактивна и предпочитана 
туристическа дестинация. В потвьржление на тезата, могат $\Delta а$ бъдат посочени фракти, селектирани от отчет за изпьлнението на Програмата за управление на община Казанльк - 2015-2017 г., кьлето е посочено, че среА еАни от „основните цели през 2017 за изграждане на устойчив туризьм са:

1. Повишаване имилжа на града и позициониране на Казанльк като атрактивна Аестинация със собствен облик и богато културноисторическо наследство в България, страните от Европейския съюз и Аругите основни чужАестранни пазари

2. Повишаване привлекателността на общия туристически продукт на Общината, чрез благоустрояване на инораструктурата обслужваща туризма, чрез развитие на туристическите атракции, опазване и съхраняване на чистотата на околната среда на района, подобряване сьстоянието и експониране на културно-историческото наследство, както и чрез подобряване на качеството на туристическите услуги" (Godishni otcheti i publikacii, n. d.).

Споменатите по-горе фоктори Аопринасят както за утвържАаването на значимостта и актуалността на темата от глеАна точка на развитието на културния туризъм в Казанльшкия регион. Същевременно тези фактори могат да бъдат разгледани и представени в контекста за използване възможностите на новите технологии за съхраняване и популяризиране на тракийското културно наслелство, свързано с Аолината на тракийските влалетели. Използваните метоли за анализ се отнасят към контент анализ на нормативни Аокументи, законодателни решения и алминистративни решения във връзка с музейните обекти в района на граА Казан^ьк и Аолината на тракийските влалетели.

\section{Обект и преАмет на изслеАване по темата}

Обектьт на изследване се отнася към музейните обекти в Аолината на тракийските влалетели, а предметьт е влиянието на новите

\footnotetext{
1 Отчет за изпьлнението на Програмата за управление на община Казан^ьк за втората година на мандат 2015 - 2019. В: Сайт на Община Казанльк [Онлайн], (Godishni otcheti i publikacii, n. d.).
} 
технологии за социализация (инорормационни технологии; Аигитализация и Ар.) на тракийските гробници и музейните обекти, свързани с Аолината на тракийските влалетели.

Целта е установяване на възможности за популяризирането на културното наследство от Аолината на тракийските царе чрез прилагането на съвременните инорормационни и комуникационни технологии и осигуряването на интелектуален достъп Ао музейните обекти.

Хипотезата е, че с цел едективното промотиране на тракийското културно наслеАство, полобряването на обслужването и насьрчаване на посещаемостта на музейните обекти от Аолината на

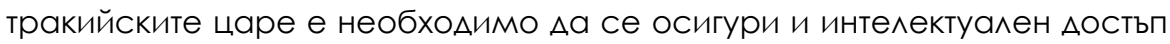
АО всички музейни обекти, както и Аа бъАат приложени съвременните ИКТ. През послеАните години Аичи все по-силно изразена тенденция, свързана с необхолимостта различните паметници на културата и открити артефракти Аа бъдат съхранявани и предавани на поколенията, превръщайки се в електронни носители на инорормация. Важен фрактор са възможностите за полобряване процесите на социализация чрез научни и технологически нововъведения в ^ицето на съвременните инорормационни технологии.

Биха могли Аа се формулират следните Аопускания:

Пьрво, осигуряването на интелектуален Аостьп Ао музейните обекти от Казанльшкия регион и прилагането на практики, предоставящи възможности за нововъвеАения пол различни интерактивни орорми, в това число виртуални разхолки, ще стимулира културния туризъм в Казанльшкия регион;

Второ, използването на технологични решения с виртуална и смесена реалност и Аруги иновации, свързани със съвременните ИКТ в музеите, успешно биха могли Аа подпомогнат развитието на културния туризъм както на местно, така и на национално ниво.

\section{Специфики на Казанлъшкия регион и Аолина на тракийските царе}

Казанльшкият регион заема важно място в политическата и културната история на България. Това се обуславя най-вече от 
географрското му положение и благоприятните природни и кАиматични

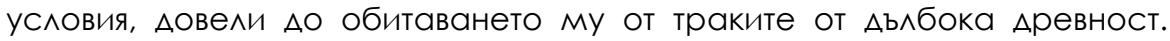
Казанльшката Аолина се намира в центьра на България межАу Авете планински вериги - Стара планина и Средна гора. СпореА писмените и материалните паметници, най-древните жители по тези земи са траките, а проучените в годините могилни некрополи свидетелстват за духовната и материалната им култура, за чиито образци може $\Delta а$ се твърли, че са без аналог в световното културно наследство.

Траките са ни оставили множество свои паметници, откриването и проучването на които попьлва археологическата карта на България. Те са познавали релица занаяти, но волещо място заемат ювелирните произвеления на изкуството каквито са различните накити прьстени, огърлици обици, гривни и Ар., отличаващи се с майсторство и начин на изработка. Не по-маловажна е и духовната им култура, Аостигнала $\Delta \mathrm{O}$ нас чрез гробниците и гробничните съорьжения и извършваните в тях погребални обреАи, за които свилетелстват множеството открити Авижими културни ценности, част от погребалния инвентар.

Концентрацията на многобройните паметници на тракийската култура имено в Казан^ъшкия регион се свързва най-вече със столицата на ОАриското царство - Севтополис, който е значим „центьр на политическата власт"2 (Dolinata na trakiyskite vladeteli..., n. d.). Също така в региона "са регистрирани нал Аеветстотин могили, като сто четиридесет и четири са разположени в източната част на Аолината"з (Dolinata na trakiyskite vladeteli..., n. d.). В голините са проучени повече от Авалесет могили като значими археологически проучвания са направени през 1944 г., когато е открита Казанльшката тракийска гробница, както и в гоАините 1992-1997 г. в Казанлъшката кот^овина и през 2004 г., когато са открити гробниците в могилите Голяма Косматка и Светица. По-голямата част от направените открития в Казанльшкия регион са от експедиция ТЕМП и имат висока научна и художествена стойност. Тяхната многобройност се Аь^жи благоларение на фракта, че

\footnotetext{
2 Могили и гробни съорьжения в Аолината на царете [он^айн], (Dolinata na trakiyskite vladeteli..., n. d.).

3 Пак там, (Dolinata na trakiyskite vladeteli..., n. d.).
} 
членовете на експедицията работят с „необикновено бързи темпове, използват геофизична и земекопна техника и има значителен сьстав от квалифрицирани калри - археолози, архитекти, геофизици, художници, реставратори и $\Delta$ р." ${ }^{4}$ (TEMP, n. d.).

СреА най-значителните открития на експеАицията в Аолината на тракийските влалетели са гробниците в „могилите Оструша, САавчова, Голяма Арсеналка, Хелвеция, Грифоните, Шушманец, Голяма Косматка и Аруги"5 (ТЕмР, п. d.). Откритията на голяма част от гробниците в Казанльшкия регион, направени от А-р Китов и експедиция ТЕМП, оставят не само трайна слеАа в Българската история и спомените на гражданите на грал Казанльк, но и Аопринасят за преврьщането на грала в значима и привличаща множество български и чужАестранни посетители атрактивна туристическа дестинация.

\section{Значимост на културното наслеАство и нормативната регламентация}

Позовавайки се на Закона за културното наслеАство, спореА чл. 3. (1) "Този закон има за цел $\Delta а$ създале условия за опазване и закрила на културното наслеАство, устойчиво развитие на политиката по

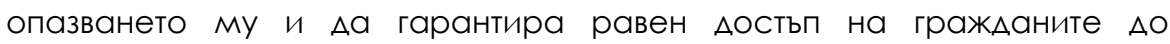
културните ценности при спазване на следните принципи: 1. равнопоставеност на различните виАове културно наслеАство при осъществяване на неговата закрила; 2. Аецентрализация на

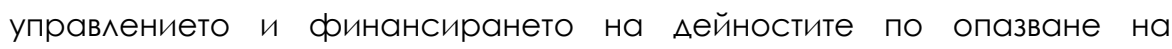
културното наслеАство; 3. публичност и прозрачност при управлението на Аейностите по опазване на културното наслеАство.

(2) Правото на Аостъп Ао културното наслеАство е възможност $\Delta a$ се ползват културните ценности, като се осигури фоизически или интелектуален Аостъп Ао тях, без Аа се уврежАат или пол^агат на риск.

(3) Аьржавата, общините и частните лица съзАават условия и гарантират на всяко лице равен Аостьп Ао културни ценности.".

\footnotetext{
4 ТЕМП. В: Траколожка експеАиция за моги^ни проучвания [Он^айн], (ТЕMP, n. d.). 5 Пак там, (TEMP, n. d.).

6 Закон за културното наследство
} 
Анализирайки цитирания по-горе Аокумент може да се направи Аопускането, че музейните обекти трябва $\Delta a$ се стремят бъ $а т$ поставени в основата на развитието на устойчив културен туризъм и опазване и популяризиране на тракийското културно наслеАство. Не помалко важно е и осигуряването на равни възможности за Аостьп $А$ о обектите, които $А$ п предоставят на своите посетители условия както за ффизически, така и за интелектуален Аостьп от всички виАове целеви групи, вкАючително на хора със специални потребности.

Относно публичността и прозрачността е от важно значение за полобряването и социализацията на музейните обекти Аа бъдат организирани повече съвместни Аейности и инициативи с Аруги културни Институции, вкАючитеАно на национаАно и межАународно ниво. Чрез участието в различни събития като например изложения, изложби и Аруги, от еАна страна биха могли $А$ с се полпомогнат процесите на популяризиране на културното наследство от Казанльшкия регион, а от Аруга страна $А$ б бъле стимулиран обменът на Аобри практики както на национално, така и на межАународно ниво, а не на последно място, разбира се, да бъдат промотирани и популяризирани среА широката общественост.

\section{Тракийското културно наслеАство и законовата регламентация}

Говорейки за Казанлъшкия регион с препратки към Закона за културното наслеАство, бихме могли Аа твърАим, че тракийското културно наслеАство съзАава преАпоставки и притежава висок потенциал за развитие на културен туризьм поради разнообразните по виА културни форми и културно сьльржание, които сьчетава и преАлага. Казан^ък е основно промотиран и популярен през Ава основни символа, а именно розата и траките които са емблематични и значими както за местната общност, така и за националното и световното културно наслеАство.

Според исторически сведения, Казанльшкия регион е заселен още от Аьлбока Аревност и именно тук са открити множество материални следи, свьрзани с траките и тяхната култура. Разкритите гробни съорьжения впечатляват със своето разнообразие и майсторството при изпьлнението и украсата им. 
Всички гробници от Аолината заедно с Аревната столица на олрисите - Севтополис, преврьщат района в място с висока концентрация на интересни и атрактивни паметници от тракийската епоха в България, което обуславя и необходимостта от тяхното опазване, социализиране и популяризиране като обекти от национална и световна значимост.

Порали всички тези фрактори е необхолимо $а$ се работи в посока за осигуряване на равни възможности на всички посетители не само за фризически, но и за интелектуален Аостьп Ао музейните обекти.Говорейки за интелектуалния Аостьп, може $л а$ се каже, че се отнася още кьм т.нар. Аигитална Аостьпност. Чрез различни цифрови средства музеите и организациите, занимаващи се с опазването и популяризирането на културно наслеАство, биха могли Аа увеличат възможностите за Аостьп АО тях, които бяха немислими АО преАи няколко гоАини. Не само чрез интернет музеите в социалните меАии могат $\triangle$ а Аостигнат $А$ нова и различна аудитория. Благодарение на технологиите те могат $\Delta$ a алаптират инорормацията към специфичните характеристики, интереси, профии и очаквания на посетителите, както и Аа АОпьАнят фризическите посещения, преАоставяйки им Аопьлнителен Аостьп Ао материали, които $а$ се използват Аистанционно. Например АОстьпьт в Интернет АО различни ЗD моАели позволява отблизо и в Аетайли Аа бълат разглелани разнообразни по виА обекти. Ето защо музеите като „институции, служещи в полза на обществото, трябва $А а$ разглежАат и осмислят Аостьпността като свой основен, приоритетен и Аългосрочен ангажимент" (Making Heritage Accessible..., 2018).

\section{Приложение на новите технологии в музейните обекти}

Налагането и употребата на иновативни бази Аанни в интернет от културните институции, спомага за улесняването на Аостьпа $А$ о инорормация, както на служещите в Аалената институция, така и на посетителите, преврьщайки ги с развитието на технологиите в потребители.

С течение на времето мичат тенденции в развитието на базите от Аанни, изразени най-вече в улесняването и вьзможността за по-бърз Аостьп АО необхо имата информация. На слеАващо място е от важно значение $а$ бъдат използвани повече иновационни технологии, които 
биха могли Аа полпомогнат улесняването както на научната обработка на различните открити в Аолината на тракийските царе артефракти, така и популяризирането им. Важно е да отбележим, че съвременните инорормационни технологии не пречат на традиционните носители на инорормация, а дори напротив, тяхната цел е $А$ ги усъвьршенстват и налгражАат. Съвременното развитие на науките изисква прилагането на инорормационните науки и технологии за точното и цялостно интерпретиране на богатото ни наслеАство от различните исторически периоли. С помощта на подобни нововъведения би могло $А$ се улесни в известна степен Аостьпа и популяризирането както на музейните обекти от Аолината на тракийските царе, така и на направените в тях открития. Миналото няма как да бъле върнато назал, нито сьществуват възможности да бъде променено. За сметка на това високото обществено значение което има, поражда необходимостта от съхраняване на националната памет и предаването и на поколенията. Сьщо така е важно Аа се има предвил, че осигуряването на Аостьп Ао мултимедийно сьдьржание с инорормация за културно-историческите обекти от Аолината на тракийските царе или предоставяне на вьзможности за виртуално персонализирано пьтуване Ао музейните артефракти с помощта на съвременните инорормационни и комуникационни технологии, би могАо Аа осигури възможности за Аостьп на потребителите (посетителите) Ао цифрово сьдьржание и разнообразни видове мултимеАия, в това число аудио и видео, както и снимков материал, свързан с музейните обекти от Аолината.

За осигуряването на интелектуален Аостьп АО тракийското

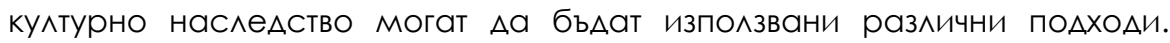
Такива например са приложението на виртуанна реалност, виртуални турове, 3D възстановки като модерен начин за представяне на културното наслеАство и Аруги подходи чрез които може $а$ б бь $А е$ привлечена по иновативен начин музейната публика.

„В голяма част от нашите музеи, нещата се представят като във витрина на магазин, а трябва да се има предвил, че представянето на 
експонатите в съответния контекст е много по-вълнуващо за публиката"7 (Da predstavish..., n. d.).

Говорейки от Аруга страна за осигуряването на интелектуален Аостьп за целевата група и профила на туристите в мицето на наймалките посетители на музея, е важно да се има предвил, че за тях е "Много важно $а$ а има т.нар. интерактивни кътове или работилници,

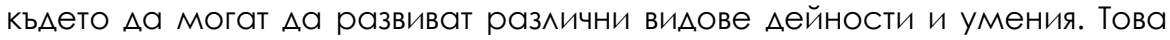

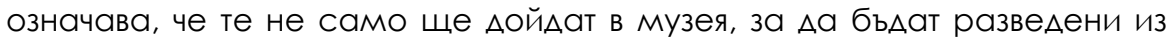
залите, но това посещение би могло $а$ бъле свързано с определен тип Аейност, в която Аецата могат $а$ а бълат в ролята на реставратори, $\Delta а$ работят с разнообразни материали и Ар., като от значимост е и наличието на нови технологии, 3D представяне на експонатите и т.н"8 (Savremennite tehnologii, n. d.). По този начин се биха могли $\Delta а$ бълат активизирани и образователните функции на музейните обекти, което Аа разшири обсега на посещаемостта от различни целеви групи и полобри тяхната социализация.

Не по-малко значима е и необходимостта от работа в посока за промотиране, рек^ама, повишаване на популярността и имилжа на културните обекти, както и за увеличаване на посещаемостта в тях в зависимост от различните профоили на туристите.

Това би могло да бъле постигнато чрез алаптирането на интерактивни практики, Аопьлващи традиционното представяне на тракийското културно наслеАство, които биха могли $А$ бъ $а т$ приложени пол различни форми като част от образователни музейни програми, събития, свьрзани с културния календар на ИМ „Искра“ и Община Казанльк и Аруги молели за социализация.

Бихме могли да направим Аопускането, че приложението на новите технологии в музейните обекти би могло $\Delta а$ бъде практически реализирано чрез преАлагането на възможности за Аостъп условно обособени на Аве равнища. На пьрво място музейните обекти биха могли Аа съзаават възможности за Аистанционно посещение пол формата на

\footnotetext{
7 Аа представиш културното наследство чрез иновативни метоли [online], (Da predstavish..., n. d.).

${ }^{8}$ Съвременните технологии - възможност музеите да станат по-атрактивни за Аецата. B: БHP [online], (Savremennite tehnologii, n. d.).
} 
обособени виртуални музеи, както и Аа осигуряват електронен Аостьп Ао интернет линкове с виАео фрилми, препратки към социални мрежи, Ютюб и инстаграм канали, файсбук страници и Аруги, промотиращи разнообразното културно наслеАство на Казан^ьшкия регион, вКАючително преАставящи по иновативен начин богатата тракийската култура. На следващо място в самите музейни обекти с оглеА развитието на съвременните технологии биха могли Аа бъАат обособени и преАложени възможности на посетителите Аа превьрнат посещението на обектите в запомнящо се преживяване. Много сьвременни музеи все по-активно насочват експозиционната си Аейност към интерактивност като вътре в музейните обекти преАлагат на посещаващите ги $А$ р реализират срещата с миналато чрез виртуална, Аобавена или смесена реалност.

\section{Заключение}

В заключение на всичко казано до тук е важно да кажем, че социализацията на музейните обекти и осигуряването на интелектуален $\triangle$ Остьп АО културното наслеАство от Аолината на тракийските царе е от особено важно значение за опазването и популяризирането на културното наслелство, защото то е не само наслелство на Казанльшкия регион и на България, а сьщо така е част и от световното културно наслеАство.

Аолината на тракийските царе в Казанльшко е еАин от Аобрите примери за атрактивна туристическа Аестинация от световна величина. Порали тази причина е необходимо да бъдат обособявани повече иновативни практики, които Аа подпомагат процесите, свързани с опазването и социализацията на обектите и предаването на културната памет и наследство на поколенията за бъдещето. Всичко споменато в разработката е валиАно и актуално към тематиката за социализацията и осигуряването на интелектуален Аостьп с помощта съвременните ИКТ и приложението им за популяризирането на тракийското културно наслеАство.

Аосегашната Аейност би могла Аа бъле осмислена и в посока нововъвеАния, среА които Интерактивни фоорми, виртуаАни разхоАКи, активно използване на социалните мрежи, технологични решения, виртуална и смесена реалност. Всичко това може да бъле приложено 
за популяризирането и утвьржАаването на Казанльк като туристическа Аестинация с местно, регионално, национално и световно значение и за създаването на устойчив културен туризьм.

\section{AИTEPATYPA / REFERENCES}

Godishni otcheti i publikacii, (n. d.). Otchet za izpalnenieto na Programata za upravlenie na obshtina Kazanlak za vtorata godina na mandate 2015 - 2019 (in Bulgarian). [https://www.kazanlak.bg/page-6388.html, (Last view: 01.06.2020)] // [Отчет за изпьлнението на Програмата за управление на община Казан^ьк за втората голина на мандат 2015 - 2019. В: Сайт на Община Казан^ък [Он^айн]].

Dolinata na trakiyskite vladeteli..., (n. d.). Mogili i grobni saorazheniya $\vee$ Dolinata na tsarete (in Bulgarian). [http://traciantombs.blogspot.com/2013/08/grobnitesorjeniya-v-dolinata-na-carete.html, (Last view: 21.06.2020)] // [АOАИHATA HA ТРАКИЙСКИТЕ ВАААЕТЕАИ: МогИ^И и гробни съоръжения в АоАината на царете / Могили и гробни съоръжения в Аолината на царете [он^айн]].

TEMP, (n. d.). Trakolozhka ekspeditciya za mogilni prouchvaniya (in Bulgarian). [http://www.thracetemp.org/, (Last view: 29.06.2020)] // [ТЕМП. В: Трако^ожка експелиция за могилни проучвания [онлайн]].

Making Heritage Accessible: Museums, Communities and Participation, (2018). Making Heritage Accessible: Museums, Communities and Participation, [https://rm.coe.int/faro-convention-topical-series-article-5-making-heritageaccessible-mu/16808ae097, (Last view: 01.06.2020)].

Da predstavish kulturnoto nasledstvo chrez inovativni metodi, (n. d.). Da predstavish kulturnoto nasledstvo chrez inovativni metodi (in Bulgarian). [https://www.bloombergtv.bg/nachalo/2018-06-19/da-predstavish-kulturnotonasledstvo-chrez-inovativni-metodi, (Last view: 01.06.2020)] // [Аа преАставиш културното наследство чрез иновативни метоли [online]].

Savremennite tehnologii, (n. d.). Savremennite tehnologii - vazmozhnost muzeite da stanat po-atraktivni za decata (in Bulgatian). [http://bnr.bg/radiobulgaria/post/100234670/syvremennite-tehnologiivyzmojnost-muzeite-da-stanat-po-atraktivni-za-decata, (Last view: 01.06.2020)] // [Съвременните технологии - възможност музеите Аа станат поатрактивни за Аецата. В: БНР [online]]. 


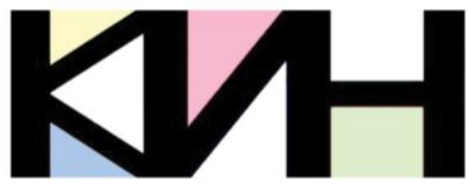

КУАТУРНО-ИСТОРИЧЕСКО НАСАЕАСТВО:

ОПАЗВАНЕ, ПРЕАСТАВЯНЕ, АИГИТААИЗАЦИЯ

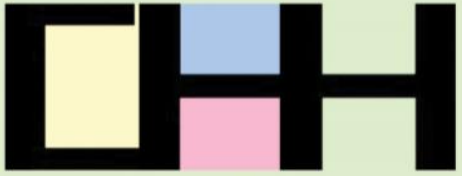

CULTURAL AND HISTORICAL HERITAGE: PRESERVATION, PRESENTATION, DIGITIZATION
Материалите в сборника са обект на авторско право. Разрешава се безвъзмезАното ползване на техни електронни/ хартиени копия само за лична употреба или обучение, при пь^но цитиране на текущата страница и слеА писмена декларация от цитиращия за мипса на търговски намерения.

(с) Авторски колектив, 2020

Техническо реАактори: Калина Сотирова-Вълкова Николай Ноев Паска^ Пиперков

\section{Editors}

Petko St. Petkov

Galina Bogdanova

This work is subject to copyright. Open and free of charge use of digital/hard copies of publications is granted only for personal or educational use, with full citation of the current page, and after written declaration of the quoting side for notcommercial Intention.

(C) Authors` Group, 2020

Technical editors:

Kalina Sotirova-Valkova

Nikolay Noev

Paskal Piperkov

НАЦИА регистрационен № 1209

Научна пореАица: том 6, брой 2 (9)/2020

Science series: vol. 6 , issue $2(9) / 2020$

NCID Registry No. 1209

www.math.bas.bg/vt/kin

ISSN: 2367-8038 